\title{
Diclofenac Induced Paroxysmal Atrial Fibrillation
}

Hızır Okuyan

Department of Cardiology, Başkent University Konya Application and Research Centre, Konya, Turkey

Cite this article as: Okuyan H. Diclofenac Induced Paroxysmal Atrial Fibrillation. J Emerg Med Case Rep 2018; 9(4): 80-2.

\begin{abstract}
Introduction: Diclofenac sodium is commonly used medication for pain relief and reducing inflammation. Adverse effects of diclofenac are well defined in the literature but none of the patients described previously in the literature presented with diclofenac induced paroxysmal atrial fibrillation (PAF) as in our case.

Case Report: A 48 year old male admitted to emergency department with severe headache. The patient had history of migraine. Physical examination of the patient revealed no pathologic sign and $75 \mathrm{mg}$ diclofenac sodium administered intramuscularly for headache. He had severe attack of palpitation and dispne 20-30 minutes after administrating diclofenac sodium. Electrocardiography was consistent with atrial fibrillation (AF) with the ventricular rate of 140 beats/min. The patient's heart rate was controlled. The patient's rhythm returned to sinus rhythm spontaneously after 12 hours.

Conclusion: The most common sustained arrhythmia is AF. The estimated prevalence of AF is $0.4 \%$ to $1 \%$ in the general population. Studies showed that $40.2 \%$ of patients with AF was PAF. Underlying cause of PAF is similar to causes of sustained AF. Any report about PAF due to diclofenac was not reported before in the literature. It should be taken into account that diclofenac may cause PAF.
\end{abstract}

Keywords: Diclofenac, adverse effects, paroxysmal atrial fibrillation

Received: 10.05.2018 Accepted: 12.06.2018

\section{Introduction}

Diclofenac sodium is commonly used for relieving pain and reducing inflammation. The adverse effects of diclofenac are well defined in the literature, but none of the previously described patients in the literature presented with diclofenac-induced paroxysmal atrial fibrillation (PAF), as in our case. Herein, we present the case of a patient in whom PAF was induced due to the administration of 75-mg intramuscular diclofenac sodium.

\section{Case Report}

A 48-year-old male was admitted to the emergency department with severe headache. Verbal consent is taken from the patient. The patient had a history of migraine; however, he had no history of other chronic diseases, including cardiac diseases. Physical examination of the patient revealed no pathologic signs, and $75-\mathrm{mg}$ diclofenac sodium was administered intramuscularly for headache. He had a severe attack of palpitation and dispne 20-30 minutes after diclofenac sodium administration. Electrocardiography was consistent with atrial fibrillation (AF), with a ventricular rate of 140 beats/min (Figure 1). There was no significant change in the ST-T segments. Physical examination was normal except for tachycardia and irregular pulse rhythm. Laboratory investigation revealed that complete blood count and routine biochemical blood levels were within normal limits. There were no pathological findings on chest X-ray. Left ventricular ejection fraction was normal in transthoracic echocardiography. The patient was monitored and then administered 25-mg diltiazem intravenously in the emergency department; the heart rate was then controlled. Enoxaparin sodium at a dose of $60 \mathrm{mg}$ was applied subcutaneously. The patient's rhythm returned to sinus rhythm spontaneously after 12 hours (Figure 2). Troponin and cardiac enzyme levels were monitored for evaluating acute

Address for Correspondence:

Hızır Okuyan, Department of Cardiology, Başkent University Konya Application and Research Centre, Konya, Turkey

E-mail: hizirokuyan@gmail.com

oCopyright 2018 by Emergency Physicians Association of Turkey - Available online at www.jemcr.org 


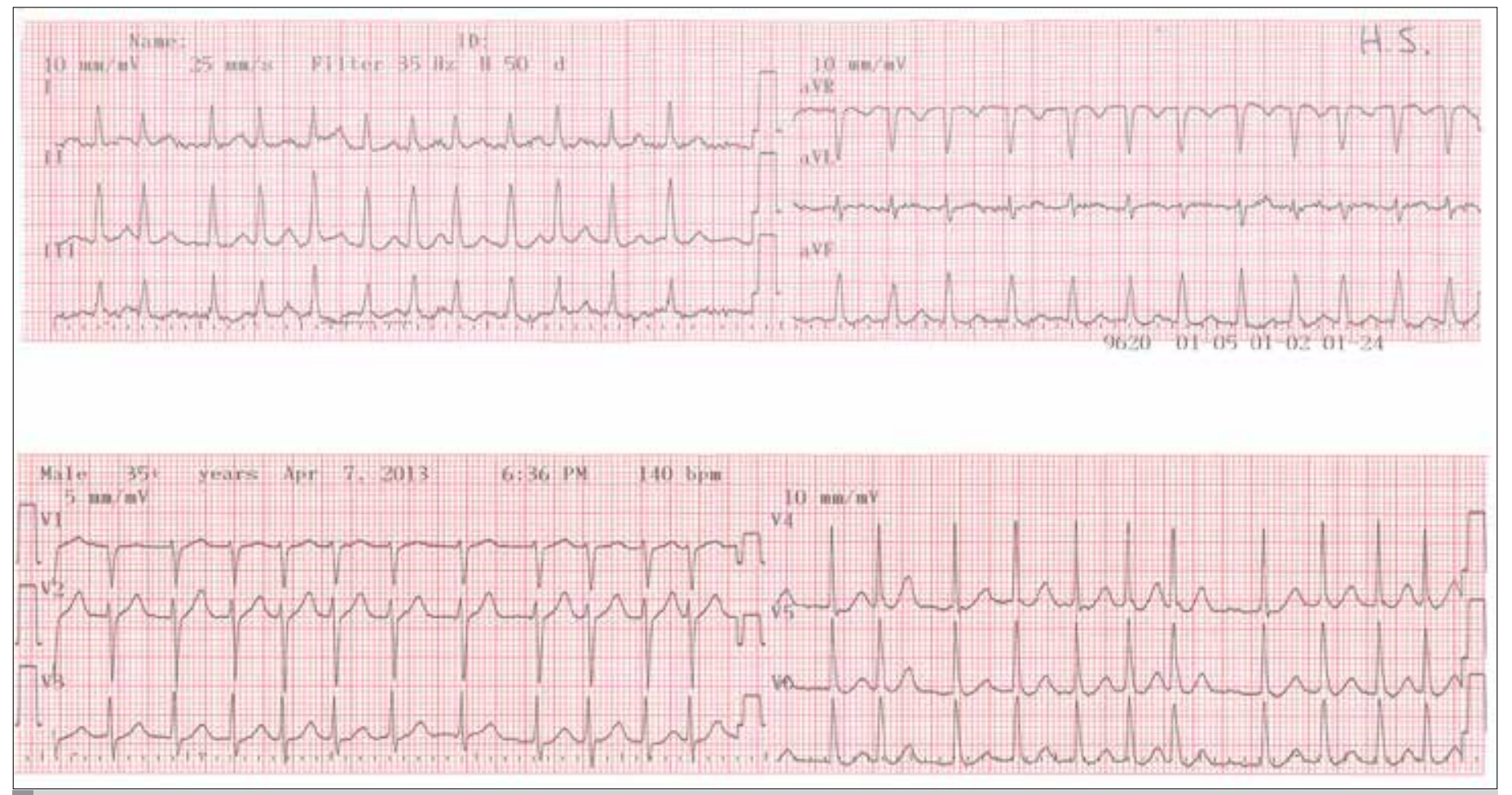

FIGURE 1. Atrial fibrillation with high ventricular response.

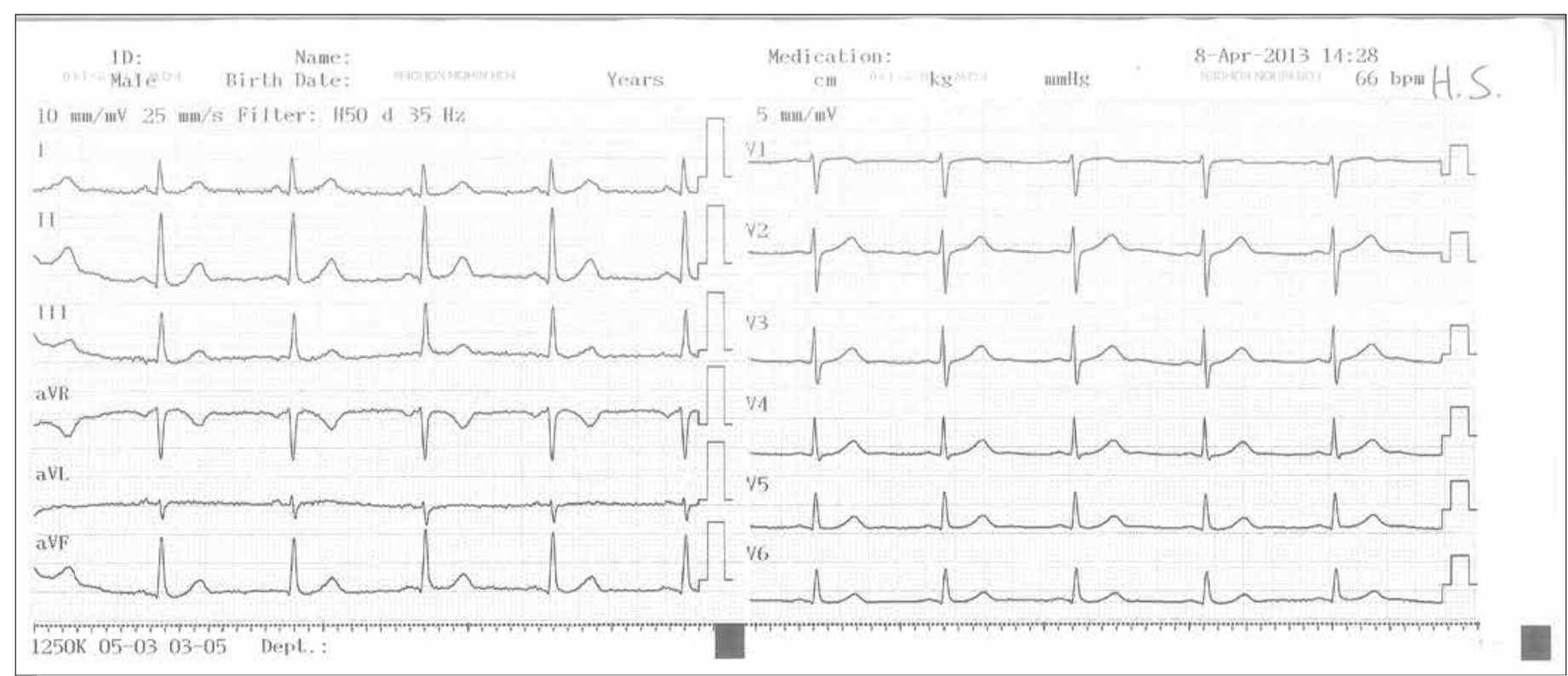

FIGURE 2. Electrocardiography depicted normal sinus rhythm.

coronary syndrome; these levels were found to be within normal limits. The patient was discharged with a prescription of 100-mg oral acetyl salicylate daily.

\section{Discussion}

Diclofenac sodium is a non-steroidal anti-inflammatory drug (NSAID) commonly used in treating a variety of acute and chronic pain and inflammatory conditions. The most common side effects of diclofenac administration are gastrointestinal symptoms, such as stomach pain, constipation, diarrhea, and dyspepsia (1). It has been accepted that the cardiovascular side effects of diclofenac are uncommon. Registries and meta-analysis showed that diclofenac increases vascular events [hazard ratio (HR): 1,6], myocardial infarction (HR: 1,54), and mortality (HR: 2,4) versus placebo or no treatment (2-3). It may not cause a problem in individuals who are at a very low risk of heart attack; however, those who have experienced heart attack in the past must avoid diclofenac because it increases the risk significantly (3). 
The most common sustained arrhythmia is AF. The estimated prevalence of AF is $0.4 \%-1 \%$ in the general population, and its incidence increases with age. Takahashi et al. (4) showed that $40.2 \%$ of patients with AF had PAF. The underlying causes of PAF are similar to the causes of sustained AF. These are hypertension, atherosclerosis, and mitral stenosis (4). The induction of PAF due to diclofenac has not been reported previously in the literature. In a case-control study, researchers found that the use of NSAIDs was significantly associated with an increased risk of AF or flutter compared with non-users NSAIDs increase risk of arrhythmia approximately $40 \%$ (5).

The mechanism of AF caused by diclofenac sodium remains unknown. Acute pain results in autonomic activation, which can precipitate atrial tachyarrhythmias (6). Additionally, systemic inflammation has been shown to be an independent risk factor for AF (7). Furthermore, AF may be induced by the direct effect of diclofenac sodium on the heart.

\section{Conclusion}

As in our case, PAF can occur due to diclofenac sodium administration, and awareness about this adverse effect of diclofenac sodium administration is important.

Informed Consent: Verbal informed consent was obtained from the patient who participated in this study.

Peer-review: Externally peer-reviewed.
Conflict of Interest: The author has no conflict of interest to declare.

Financial Disclosure: The author declared that this study has received no financial support.

\section{References}

1. Ciccolunghi SN, Chaudri HA, Schubiger BI. The value and results of long-term studies with diclofenac sodium (Voltarol). Rheumatol Rehabi. 1979; Suppl 2: 100-15.

2. Kearney PM, Baigent C, Godwin J, Halls H, Emberson JR, Patrono C. Do selective cyclo-oxygenase-2 inhibitors and traditional non-steroidal antiinflammatory drugs increase the risk of atherothrombosis? Metaanalysis of randomised trials. BMJ 2006; 332: 1302-8. [CrossRef]

3. Gislason GH, Jacobsen S, Rasmussen JN, Rasmussen S, Buch P, Friberg $J$, et al. Risk of death or reinfarction associated with the use of selective cyclooxygenase-2 inhibitors and nonselective nonsteroidal antiinflammatory drugs after acute myocardial infarction. Circulation 2006; 113: 2906-13. [CrossRef]

4. Takahashi N, Seki A, Imataka K, Fujii J. Clinical features of paroxysmal atrial fibrillation. An observation of 94 patients. Jpn Heart J 1981; 22: 143-9. [CrossRef]

5. Schmidt M, Christiansen CF, Mehnert F, Rothman KJ, Sorensen HT. Non- steroidal anti-inflammatory drug use and risk of atrial fibrillation or flutter: population based case-control study. BMJ 2011; 343: d3450. [CrossRef]

6. Bettoni M, Zimmermann M. Autonomic tone variations before the onset of paroxysmal atrial fibrillation. Circulation 2002; 105: 2753-9. [CrossRef]

7. Issac TT, Dokainish H, Lakkis NM. Role of inflammation in initiation and perpetuation of atrial fibrillation: a systematic review of the published data. J Am Coll Cardiol 2007; 50: 2021-8. [CrossRef] 